\title{
AC 2009-325: A COURSE IN COMMUNICATION AND CREATIVITY FOR UNDERGRADUATES IN ENGINEERING: SEEING AND HEARING--COMMUNICATING WITH PHOTOGRAPHS, VIDEO, AND SOUND
}

Helen Donis-Keller, Franklin W. Olin College of Engineering 


\section{A Course in Communication and Creativity for Undergraduates in Engineering: Seeing and Hearing: Communicating with Photographs, Video and Sound}

introduction

Given the global reach by employers for engineering professionals, creativity, innovation and the ability to communicate effectively have gained importance as assets of the American engineering workforce. Furthermore, while writing remains an essential means of communication, visual digital technologies such as video and still photography have gained widespread acceptance and are now ubiquitous as primary modes for communication, notably via web-based means. Despite recognition for the need to embrace "new media" courses that directly address creativity and effective communication using such tools are not plentiful within the engineering curriculum. There are many competing interests that influence curriculum design that will equip the next generation of engineers to be technically competent, competitive in the global economy, and effective as responsible citizens. The Association of American Colleges and Universities report College Learning for the New Global Century (2007), acknowledges the needs for all college students to prepare for twenty-first-century challenges by gaining four essential learning outcomes: 1) knowledge of human cultures and the physical and natural world, focused by engagement with big questions, both contemporary and enduring 2) intellectual and practical skills, including inquiry and analysis, critical and creative thinking, written and oral communication, 3) personal and social responsibility, including foundations and skills for lifelong learning, ethical reasoning and action, intercultural knowledge and competence and 4) integrative learning, including synthesis and advanced accomplishment across general and specialized studies. For Engineering students in particular educators have recognized that a narrow focus on acquiring technical skills is no longer sufficient training for the twenty-first century engineer. As several reports from the National Academy of Engineering attest (2004, 2005), in a call to action to for engineers "who are broadly educated, who see themselves as global citizens, who can be leaders in business and public service, and who are ethically grounded" Furthermore these reports go on to state that "attributes needed for the graduates of 2020 include such traits as strong analytical skills, creativity, ingenuity, professionalism, and leadership." In particular creativity is seen as "an indispensable quality for engineering as is good communication", which is defined as "the ability to listen effectively as well as to communicate through oral, visual and written mechanisms. Modern advances in technology will necessitate the effective use of virtual communication tools." Courses in the arts, humanities, and social sciences (AHS) can address the need, at least in part, for broadening the educational base for engineering students. AHS courses that focus on the development of creativity, multiple means of effective communication, improving critical thinking skills, and engagement by students with the larger questions of living within contemporary society today would address some of the important concerns enunciated in these reports. However, AHS courses form an exceedingly small fraction of the total number of course credits required for graduation. Therefore, it is important that these courses address the educational goals for engineers as effectively and comprehensively as possible. 
I propose a unique first year foundation course, designed specifically for engineering students, which facilitates the development of communication skills, individual creativity, critical thinking and writing, and requires that students contextualize their work with respect to professionals in the field and the world at large. My course, titled "Seeing and Hearing: Communicating with Photographs, Video and Sound", fulfills a first year foundation requirement in AHS and provides a project-based, student-centered learning environment that is primarily focused on the development and representation of ideas embodied in creative works of art. The AHS foundation courses at Olin College are defined by a common set of goals (established by the AHS faculty) that include the development of student writing, presentation, critical reading and writing and discussion skills; the opportunity for students to approach topics with the methods and perspectives of different disciplines; and the introduction of lifelong learning opportunities via student-motivated projects. Commonalities shared with all AHS foundation courses at Olin are writing workshops, writing assignments, final/creative projects, class discussions, reading/viewing visual work analytically, and by engaging in peer critical commentary (AHS Foundation Course Commonalities, 2007). My course fulfills the AHS commonality goals but differs in other respects to the AHS foundation courses at Olin and it differs considerably with respect to art courses taught at other colleges and universities. In the Seeing and Hearing course students improve their communication skills and develop a personal vision making use of contemporary digital media tools as vehicles for expression. One of the unusual aspects of the course as compared to art courses in other schools is that photography, video, audio and writing are offered in a single course, whereas other schools normally offer a single medium per course, and they are not structured with engineering students in mind. The combination of media serves at least two functions. It emphasizes the development of an idea followed by selection of the most appropriate means to realize the idea (from at least four forms of media). It also provides an introduction to the use of several types of media in a single class rather than requiring that a student take three or four introductory classes, something that may not be possible in the undergraduate engineering curriculum. Students also learn, by studying work of professional contemporary artists, the components of professional practice in these fields, and it is expected that students will come to realize that art has an important place in education and for life in contemporary society. The course differs from other AHS courses at Olin because it is not primarily focused on text-based analysis. However, the course meets the standards for writing commonality in the number and type of writing assignments that are required. In addition to intense concentration on the communication competency, development of life-long learning skills is emphasized and context is provided by readings, lectures, and analysis of non-fiction films. The course, which has been offered regularly since 2002, culminates with an exhibition of visual work and a screening of video projects. In this paper I describe the elements of the course, its implementation at our College with examples of student work, assessment tools, course evaluations, and plans for dissemination of the course materials to interested educators.

elements of the course

overall learning objectives and competencies addressed

This project-based class is essentially about the communication of ideas through the making of works of art. The overall objective is to improve one's ability to "see and hear" and to be able to translate a personal vision into a form that can be understood by others. The means by 
which an art object is created, i.e. process, can often contribute to the overall quality. Key to our process is developing an ability to provide objective helpful criticism to colleagues and to receive and benefit from comments of one's peers. Understanding the nature of the tools that we use to communicate will enhance our ability to make the best use of the materials at hand, therefore we should become familiar with state-of-the-art technologies for digital capture and editing, and we investigate the scientific and engineering basis of seeing and hearing. Competencies directly addressed in this course are communication (visual, written, and aural) and life-long learning (researching and learning topics independently).

the philosophy and main objectives for the course are embodied in the following specific learning objectives:

\section{Learn how to make art that reflects enlarging of one's awareness and} communicates one's intent.

The major objective for each student in the course is to make art that effectively communicates the students' intent. Students will learn how to communicate ideas through the making of art objects. Students will make original works of art using as media digital photography, video, and sound. The projects include a photographic self-portrait, a staged narrative project, and a documentary video project. By mid-semester students should have developed skills in how to 1) assess their own work and that of other students, 2) provide and receive objective criticism, and 3) translate criticism into improvements in an evolving artwork. By the end of the course students should be able to 1) describe a rational thought process for making the works of art and defend decisions made in the development of the project and 2) locate their own work within the context of work of other contemporary artists.

\section{Learn how to use tools for art making and learn how the tools work}

Over the course of the semester students should develop basic technical facility with artmaking tools: For art photography each student should learn the basics of how to 1) use a digital camera, 2) manipulate image files using Adobe Photoshop and Adobe Lightroom software, and 3) make digital prints. For sound: each student should learn the basics of how to 1) use a recorder and microphone, 2) edit sounds using Pro Tools software and video audio software. For video: each student should learn the basics of how to 1) use a digital video camera, 2) edit digital video footage using Adobe Premiere Pro software.

\section{Improve critical thinking ability.}

Develop critical thinking skills about art and ideas. For example, each student should be able to discuss, analyze, and compare the work of several contemporary artists whose work is photo-based. Students will become familiar with the work of a number of documentary filmmakers and they will develop the ability to evaluate the work based on the content, effectiveness of communication, and on technical merit.

\section{Improve written communication.}

Students will improve their analytical writing and reflective writing by the preparation, revision, and resubmission of writing projects such as critical analysis of documentary films, personal artist statements, and documentary project plans.

overall structure of the course 
A typical class size is fourteen students and one instructor supported by a student teaching assistant, a student writing tutor, a professional writing consultant, and sometimes a part-time audio/visual staff person who maintains hardware and software. Although a single instructor leads the course at our institution, team teaching would be quite feasible and in some cases preferable so that different perspectives are integrated with the teaching. This one-semester course carries four credits and meets twice per week for approximately two hours each session. Students are expected to invest at least six to eight hours outside of class on assigned reading, viewing nonfiction films, working on major projects and on other weekly homework assignments. In-class time is spent on critique sessions, writing workshops, library research tutorial, seminars by professionals in the field, and discussions of lecture material and assignments. The course begins with an introduction to fine art photography and students immediately begin making images and prints themselves using equipment that is supplied to them (if they do not own digital cameras and tripods that meet our criteria). Students are introduced to digital audio recording and editing approximately one month after digital photography has been initiated and finally video recording and editing is phased in approximately at the two-thirds point in the course. From the first meeting of the course students begin viewing documentary or non-fiction films and developing critical thinking skills by analysis of the films. The films serve as examples to inspire their own work later in the course and they provide context for issues in contemporary society.

Assessments include the weekly critique and written feedback of homework and major project work using structured rubrics (see below and figures). The course culminates with exhibitions of the visual work and a screening of the audio and video projects. There are no course prerequisites and no formal training in art or expertise with digital media is expected. This course is presently listed as a foundation course in the Arts, Humanities and Social Sciences (AHS) and represents one of five or six AHS course choices for entering first-year students. Previously the course was listed as an elective open to any grade level. When the course was changed to an AHS foundation course a significant writing component was added.

process: the critique method

Key to developing the imagination and fostering creativity in a supportive environment is a process that has as its goal a way to improve the student's ability to communicate effectively by visual or other means. I call this process the "critique method". With this process students learn to actively engage with the work of their peers and to formally comment on it with the goal of helping peers to improve their work and in the process learning how to improve their own work. This form of verbal collaboration can be of benefit all parties, if handled properly. During critique sessions we assess progress on work and plan the next steps for the project. Since most students are unfamiliar with the method and are often self-conscious about presenting their work to the class, I begin by simply asking each student to put the work on the board, describe to the class the intent for the image, what is "working" about the image and what the student would like to do if the project could be repeated. In this way the attention is focused on the work itself and the idea that the student was attempting to communicate. I invite the students to comment first then I provide an assessment and recommendations. At first I find that the students are unwilling to say anything "critical" about their fellow students' work, but as time passes they begin to learn how to make objective constructive criticism that helps other students to improve their work and of course, the benefit comes to each student as they present their work and receive immediate 
feedback. Students also learn quickly how to address the disconnect that sometimes occurs between what they intend an image or sequence to communicate (mean) and how it is perceived by others. When we begin work on a major project I ask students to take notes for each other at the critiques so that the comments are captured for later review, as students are not always able to internalize all of the comments while presenting the work. It is absolutely critical that all students participate in the critique and that an environment of trust and support is established and maintained throughout the semester. Students become more willing to share their innermost thoughts about their goals for the work and the creative process flows smoothly if they know that their work is taken seriously and that ridicule will not occur. This method has never failed to provide impressive results. For each class there is almost a magical moment when a student makes a creative advance and the class recognizes the triumph and renews their shared sense of purpose. Once that first event happens I know that others will follow with their own epiphanies and the class will continue to provide and respond favorably to critical remarks about their work and suggestions for improvements.

context

Several introductory lectures initiate the exploration of each media and art form by the class. For example, we begin by looking at a wide variety of work by contemporary fine art photographers learning about their process, their goals and the analysis of the work by art historians and other writers on art, or by viewing documentary features on particular artists, e.g.

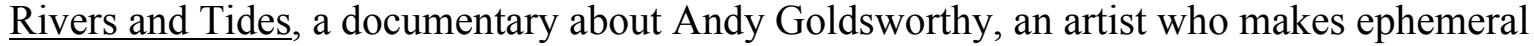
environmental works for which the photograph is the only lasting evidence of the work. A visual vocabulary is developed over time and students become familiar with the work of some of the leading contemporary artists throughout the world who employ photography. Documentary films are chosen based on subject matter as well as for models of effectiveness in editing, creative approach, use of audio etc. These films also serve as a starting point for discussions and analytical writing about topics such as the environment and man's relationship to the planet, the struggle to find one's place in the world, understanding other social groups and cultures, the experience of conflict from various perspectives, and understanding the passion that humans have for their professions and relationships. During the course of the semester students view at least a dozen documentary or non-fiction films, provide written analysis and participate in class discussion. For example, some of the films that have been included as part of the course in recent years include Fast, Cheap, and Out of Control by Errol Morris, a film that explores universal themes such as how humans create purpose and meaning for themselves through dedication to a profession, the fragility of life, and man's relationship to the environment as demonstrated by the biographies of four men who could be considered obsessed with their life's work; Murderball by Dana Adam Shapiro, Jeffery Mandel and Henry Alex Rubin; a film that examines adaptations made by disabled men and the significance of wheel-chair rugby to their redefinition as humans; Darwin's Nightmare by Hubert Sauper, a film that chronicles a shocking and devastating manmade environmental, social, and cultural disaster to Tanzania and its people due to the introduction of a non-native fish to Lake Victoria; Hearts and Minds by Peter Davis, a film that explores the Vietnam conflict from the perspective of many people who were actively involved in it; Manufactured Landscapes by Jennifer Baichwal, a film that depicts large scale industrialization and pollution of land, air and water as a result; and The Sweetest Sound, by Alan Berliner, a meditation on identity. Numerous short subject documentaries are also viewed and analyzed by students in the course. 
homework assignments and major projects

Homework assignments help build critical thinking and technical skills and teach students to develop ideas within a structured framework. Some of the homework assignments are designed to support the development of major project work by subdividing the tasks and setting benchmarks. A typical homework assignment often involves a reading assignment, viewing a documentary and answering a few analysis questions, and one or two hands on assignments, e.g. making and printing several images.

There are normally three to four major project assignments that typically take several weeks to a month to complete. Students work on these projects individually and periodically we meet as a class to discuss progress and plan future investigations. The projects are more or less sequential in time but overlapping, e.g. one project may be in its latter stages while another concurrent project is in relatively early development. The first major project, due approximately five weeks after the course has begun, is a digital photographic self-portrait and artist statement about the work. This project is appropriate for any student and it is particularly relevant for firstyear students as they assert their independence as young adults and as they define themselves to a new group of peers. The final deliverable is a 13" x 19" color print of the image and electronic file along with an artist statement that has passed through several revisions. The second major visual project is a "staged narrative", a digital photographic project. This past year students were required to develop either their staged narrative or video work on the theme of sustainability. For each of the major projects students keep a "process journal" to record their progress on the project and reflections on various directions taken. For the sound art piece, students record environmental sounds using hard disc digital recorders and edit them into a two-minute sound piece using ProTools, a professional level audio editing system. Less expensive laptop audioediting programs could also serve the purpose for this type of project. The major writing project is a six-page critical analysis of a documentary film such as Fast, Cheap, and Out of Control, by Errol Morris. Two writing workshops prepare students to develop thesis statements and support the thesis with evidence prior to beginning the writing project. One revision of the manuscript is a requirement. Numerous short writing projects help students solidify their understanding of building an argument and developing good language mechanics. The final major project is a documentary, limited to five minutes total running time, on any topic that is of interest to the students. Students prepare for this project by writing a detailed proposal for the project prior to beginning to collect footage. Students edit their video projects on personal laptops using commonly available software such as Adobe Premier Pro. The final deliverable is a DVD of the documentary.

assessment

On the first day of class students answer an incoming questionnaire that queries their prior experience and knowledge, e.g. one question asks for names of their favorite photographers and documentary filmmakers and reasons for taking the course. There is a mid-semester questionnaire that monitors student satisfaction and asks what the professor can do to aid student learning and what the student can do to assist with learning. At the end of the semester there is a relatively detailed student evaluation of the instructor and the course, which is a standard fixture for each course at our institution, and a second more detailed questionnaire that helps shape the next version of the course (See Figure 1). In addition, I meet individually with each student to review his or her entire semester's work and to solicit verbal feedback on the course. 
Each homework assignment and major project is graded and written feedback is provided. Prior to initiating work on a project or homework assignment guidelines for the work are distributed. There is a writing rubric and a rubric for visual, auditory work, and for the video project. A writing rubric is shown in Figure 2 and a sample writing rubric that includes instructor comments on a student project is shown in Figure 3. A visual rubric with instructor comments is shown in Figure 4. The visual rubric is used to score four individual components according to three levels of accomplishment: 1) a plus is assigned if the work "meets the assignment extremely well, great job, just as expected", 2) a circle is assigned provided "You've done an acceptable job but there is room for improvement", and 3) a triangle is assigned if "There are significant problems that negatively impact the success of the project". An overall letter grade is given for each assignment and general comments are provided. For each of the major projects numerous revisions are undertaken and in some cases entirely new directions pursued until a satisfactory outcome for the project is realized. The homework assignments, particularly the initial ones, do not require revision, as the goal is to have the student engage with a question and apply what is learned to the next project.

results of implementation of the course over a six-year period

Students who enter the course are in their first semester of their first year. They choose the Seeing and Hearing course from a set of at least five offerings of Foundation courses. They are required to select one AHS Foundation course in the first semester. While some students have experience with digital photography and/or video, typically none have studied making art with these digital tools. None have been exposed to sound art and most have a need to improve their critical thinking and writing skills. Few students are regular museum visitors and most students are not able to name a single visual photo-based artists or documentary film artists when they join the course (as reported on the initial questionnaire). Occasionally a student will mention Ansel Adams as a photographer or Michael Moore as a documentary film artist on the questionnaire. Based on this initial assessment it is probably fair to conclude that formal instruction or self-study in the fine arts and particularly digital fine arts is minimal. Despite the lack of preparation, which might signal a lack of interest, most students become very engaged with the challenges of the course and some spend far more than the expected eight to ten hours outside of class working on assignments. They learn about the major practitioners in fine art photography, documentary and nonfiction films, and sound. As the examples of course work attest (see Figure 5) students produce work that is original that reaches a relatively high level of craftsmanship. Students become technically proficient with the equipment and software, skills that find application in projects for other classes, although this is not the focus of the course. More important they learn about the creative process, how professionals in the field work and think, and that they are able to develop new projects beyond the confines of the course. The course is not without its issues, however. One recurring major issue is time management on the part of the students and how it affects their ability to respond to the numerous assignments and requirements of the major projects. In some cases there is a noticeable lack of maturity by the first year students and there are struggles that each one experiences as they navigate their first college semester. Some students admit that they select the course because they think there will be less writing required by this foundation course and not because they are interested in art (there is commonality in writing assignments for all the foundation courses). When asked in an exit questionnaire in 2008 "In what way has this course contributed to your engineering education?" students comments included "allowed me to be more creative, working with new software...I 
think that it has given me a fresh perspective on many topics and taught me skills that are useful in communicating in a variety of media... Visual materials are very important in Engineering presentation, so in that way I think practice with visual and auditory communication helped with my engineering education ...It provided a great balance for the other technical classes...using equipment to make work for other classes... It has helped me learn about visual communication, which will be helpful in portraying my ideas in other classes". It would be interesting to survey students several years after taking the course to ascertain the value they place on the course with respect to other AHS courses and the entire student experience during their undergraduate years.

student evaluations

The course has been popular amongst the undergraduates and there is often a waiting list in the fall for admission. The college expects but does not require a response from each student to a course evaluation that is administered on the last, or nearly the last, day of class at the end of the semester. Answers to the questions are submitted electronically and the results returned to the instructors once the grades have been submitted to the registrar. Most students answered affirmatively when they were asked if the instructor: used time effectively, explained material clearly, helped me to think creatively about the subject, connected the course content to other subjects or disciplines, was available for help outside of class, gave useful feedback on my work, treated students fairly, responded effectively to feedback from the class, responded effectively to feedback from individual students and that the instructor was, overall, an effective teacher.

Twelve of 13 students who responded to the survey in 2008 reported that the course was challenging or highly challenging, which is consistent with previous reports by classes. With respect to the learning objectives from the past three or four classes enrolled in the course, more than $80 \%$ agree or strongly agree that they accomplished learning objective one (can make art that reflects enlarging awareness and communicating my intent), more than $85 \%$ affirmed objective two (learned how to use the tools), more than 50\% felt that objective three (improved critical thinking) had been accomplished while about $30 \%$ were neutral. Only about $40 \%$ of students thought that objective four (written communication) had improved significantly. Not surprisingly a few of the students react with negative comments about this required course for every question asked. Narrative comments from the student evaluations are usually positive. For example, "All of the assignments were very fun and really helped to build my skills. We also had a nice balance between doing our own work and learning about other artists. Peer critiquing is REALLY effective" and "Doing the projects was the best part of the course! Just being told to get a camera/microphone and go out and catch things - and then seeing what everyone else brought back, and being amazed that folks catch things in your pictures that you hadn't seen yourself...I was apprehensive about using the camera at first since I hadn't had "training" on how to photograph "correctly" before, but I definitely got over that fear". From the 2008 class, e.g. "the class was awesome, I feel like I learned a lot from the course" and "Great class, I enjoyed it very much and the assignments were incredibly fun". Dissatisfaction from students usually has to do with workload issues and not having enough time on each project.

faculty responses

The course has been a regular catalog offering for six years and approved by the Academic Review Board of the College as a foundation course for first year students, one of five or six that are offered each year. Details on the course were presented at a faculty retreat in 2007, 
however a survey of faculty viewpoints on the course has not yet been done. Anecdotal comments affirm support for the course amongst a broad segment of the faculty.

instructors and teaching support staff qualifications

It is important that the instructor or instructors have a solid education in the fine arts e.g. a masters degree in fine arts with some specialization in sound art, video and photography. Equally important is a willingness to structure the course to meet the needs and interests of students in engineering. Expertise in writing normally expected of a professor in an engineering college or university should be sufficient, particularly if support from a writing instructor is available.

teaching assistants, writing tutor and media tutor

Students who have done well in the course in previous years often serve as teaching assistants. They establish office hours for individual help sessions, schedule and give tutorials on software, and arrange screenings of the assigned documentaries. The student writing tutor is supervised by the writing consultant and assigned to the course to help students with writing drafts and revisions.

writing consultant

At our institution a professional writer from the AHS group serves as the writing consultant for all foundation courses. Duties include working with the instructor in structuring short and major writing projects, giving writing workshops, supervising writing tutors and meeting with students who have significant deficiencies in writing to help them improve, and assisting with assessments of writing assignments. At other institutions a program in writing across the curriculum with staff available to assist with training might serve the same function that a writing consultant does for our institution.

educational materials required

Introductory texts for digital photography and documentary filmmaking and editing are required for the course. For example, this past year the following texts were required.

Complete Digital Photography, 4th Edition, 2007, by Ben Long, Published by Charles River Media, ISBN-10: 1-58450-520-6

The Adobe Photoshop CS3 book for Digital Photographers, 2007, by Scott Kelby, Published by New Riders, ISBN 13: 978-0-321-50191

The Adobe Photoshop Lightroom Book for Digital Photographers, 2007, by Scott Kelby, Published by New Riders, ISBN 13: 978-0-321-49216-6

Documentary Film: A Very Short Introduction, by Patricia Aufderheide, Oxford University Press, ISBN: 978-0-19-518270-5

Additional reading lists are provided under the categories strongly recommended and recommended additional reading. Guidelines for writing and rubrics have been developed and 
are posted on the course website. Additional handouts on sound and critical analysis of contemporary art are distributed or assigned as reference material from the College library.

equipment and software requirements

For digital photography the Canon PowerShot $\mathrm{G}$ series has proven to be a very useful camera for this introductory course. The current model, the PowerShot G9, 14.7 Mp, has fully automatic and sufficient manual controls to enable students to learn the basics with a reliable piece of equipment that is relatively inexpensive (about $\$ 400$ each). A tripod and ball head, available for less than $\$ 200$ completes a kit that can be shared amongst two or, less optimally, three students. Epson printers have worked well for us. We currently have an Epson Stylus Pro 2200 color printer and a wide format Epson 9000 printer. Audio hard disk recorders, e.g. H2 Zoom are adequate and retail for less than \$200 each. Canon hard disk SDHD camcorders retail for about $\$ 500$ each and video tripods can be purchased for about $\$ 125$ each. Headsets for monitoring incoming audio for the camcorders or the audio recorders cost less than $\$ 100$ each. Our students are issued the same type of laptop, which makes compatibility with software needed for the course manageable. Adobe Photoshop and Adobe Lightroom are required for Image editing for each student in the course in addition to Adobe Premier Pro for video editing. While we have a relatively expensive ProTools audio editing workstation that all the students share, less expensive audio editing programs for laptop use would be sufficient for the purposes of this introductory course. Printer paper, inks, and SD storage cards are other necessary expenses for the course.

exporting this course to other institutions

All educational materials developed for this course are freely available to interested educators. We are currently evaluating the interest and feasibility of an on-site workshop to train educators and a course manual with syllabus, reading and viewing lists, homework and project assignments as well as rubrics and guidelines. A website for distributing material is likely to be the easiest and lowest cost means of disseminating the course materials. For further information about this course please contact the author of this report.

conclusion

This paper describes a course that has been implemented for six years at Olin College which is part of an effort to redesign engineering education so that students will be better equipped to meet the challenges of the twenty-first century. Seeing and Hearing: Communicating with Photographs,Video and Sound is a unique first year foundation course in the arts, humanities and social sciences that is designed specifically for engineering students in order to improve communication skills, to further develop creativity, and to improve critical reading and thinking. The course demonstrates a way to teach communication skills to undergraduates through the production of art works that utilize digital media. The course has been well received amongst the first year engineering students as judged from survey data. The majority of students surveyed agreed that the learning objectives have been accomplished and that they will continue to make art as a direct result of the course. The writing component continues to evolve as part of the course design. Students in general prefer the other activities to writing and less than half acknowledge that their writing has improved significantly as a result of the course. The course provides an intensive teaching and learning environment that requires dedicated resources and 
flexibility on the part of educators and students. Technology changes and new ideas for projects and course material emerge on a regular basis therefore the spirit of continuous improvement must be honored in order to keep the course fresh and responsive to the educational needs of the students and to changes in contemporary society.

This course should be exportable to other institutions that favor student-centered, projectbased learning environments with relatively small class enrollments. An initial investment in hardware and software and periodic updating as technology changes are necessary expenses in order to provide an optimal and efficient teaching and learning environment. There are several means of export that are being actively considered including educator workshops at our institution, web-based distribution of educational materials and the development of a text and workbook for educators.

citations

Association of American Colleges and Universities (2007). "College learning in the New Global Century." Report from the Liberal Education and America's Promise Initiative. Retrieved from http://www.aacu.org/advocacy/leap/documents/GlobalCentury_final.pdf. Committee on the Engineer of 2020 (2004) The Engineer of 2020:Visions of Engineering in the New Century, National Academy of Engineering.

Committee on the Engineer of 2020, PhaseII, Committee on Engineering Education (2005) Adapting Engineering Education to the New Century, National Academy of Engineering

AHS Committee (2007) "AHS Foundation Course Commonalities, March 2007", AHS committee at F.W. Olin College of Engineering 


\section{Figures}

1. End of Semester Instructor Designed Questionnaire

2. Writing Rubric

3. Writing Rubric and Example Comments on Student Work, Draft of Six-page Writing Assignment

4. Visual Rubric and Example Comments on Student Work

5. Examples of Student Projects: Self-Portraits (5 total) and Staged Narratives (4 total) with Artist Statements 


\section{Figure 1.}

\section{End of Semester Instructor Designed Questionnaire}

\section{AHS1130 Seeing and Hearing}

1. Have you met with the TA (name)? Yes__ No. If yes, please indicate area of tutorial help __ digital photography audio __ video

Please indicate in a few words your level of satisfaction:

2. Have you met with the writing tutor (name) or(name)? (Circle the name(s)). If yes, please indicate in a few words your level of satisfaction.

3. Regarding the writing section of the course, did you find the workshops helpful?

Did you think there were enough writing assignments?

How could the teaching of writing be improved?

4. In retrospect would it have been more useful to read the history of documentary early in the course rather than near the end?

5. Which assigned documentary most facilitated 1) your learning, 2) appreciation of the genre, 3) application to your own work?

6. Which assigned documentary was least helpful for your learning? Do you have a recommendation for a substitute for next year?

7. Regarding the balance of media tools used in the course would you have preferred more or less... digital photography? audio? video? comments:

8. Do you think that more tutorials in the use of media tools are needed in the course?

9. What was the most satisfying aspect of the course for you?

10. What was the least satisfying aspect of the course from your viewpoint?

11. Do you think that the panel discussion on writing should be incorporated as a standard feature of the course? Why or why not?

12. What recommendations do you have for the instructor to improve the course for next year's class?

13. Who are your favorite photographers and documentary filmmakers?

14. Looking back on your activities during the semester what do you wish you had done to maximize your learning and satisfaction in the course? 


\section{Figure 2.}

\section{AHS 1130 Seeing and Hearing Fall 2008 Writing Rubric}

\section{The paper is...}

\section{Significant and Elevates Understanding}

A. The paper has a significant argument/goal. (The reader understands why the goal matters).

B. The paper provides a level of analysis that elevates the reader's understanding of the film. (The reader learns something that was not obvious).

C. The paper includes any summary of the film as a springboard to making an analytical point. (Summary must serve an analytical purpose/goal within the structure of the paper).

\section{Goal-Driven and Structured}

A. The paper has a clearly stated goal (thesis).

B. The paper has a logical structure governed by the information the writer wants to convey. (The goal governs the organizational structure of the paper).

C. The paper consistently orients the reader in relation to the writer's goal (introductory "road map," topic sentences, transitions).

i. The introduction provides a "road map" for how the writer will relay information in pursuit of the paper's goal.

ii. Each paragraph has a main point that is identifiable in its opening sentences.

iii. The paper presents clear and smooth transitions between paragraphs that tell us how and why we have arrived at the writer's next thought

D. The body of the paper consistently and convincingly makes its argument or works toward its goal.

E. Each paragraph adds to the reader's understanding of the topic.

F. All sentences and body paragraphs are coherent and follow each other logically.

\section{Supported and Effectively Analyzed}

A. The paper provides an appropriate amount of reliable, representative, and relevant evidence to support its goal.

B. The paper provides logical and plausible analysis of evidence. (The writer does not warp or distort evidence to suit his or her goals).

C. The paper actively analyzes evidence. (The paper does not let the mere inclusion of evidence speak for itself).

i. The paper carefully introduces or frames significant evidence.

ii. The paper develops specific, detailed interpretations of evidence.

iii. The paper articulates how each particular interpretation of evidence develops or deepens the paper's stated goal(s) and claims.

\section{Executed with Clear, Engaging, and Efficient Mechanics}

A. The writer's control over grammar and punctuation facilitates clarity.

B. The writer makes clear and appropriate word choices.

C. The writer uses clear sentence constructions and phrases. (Awkward sentences and phrases do not hinder the reader's course through the paper).

D. All sentences stay on task and cover ground efficiently (e.g., avoid tangents and repetition).

E. The writer maintains an appropriate level of formality (e.g., avoids contractions, slang, overly informal voice, etc.). 


\section{Figure 3.}

\section{Writing Rubric and Example Comments on Student Work, Draft of Six-page Writing Assignment}

NAME: Student's name removed

Yellow $=$ awkward or grammar problems - something is not quite right

Turquoise $=$ confusing, need to clarify

Lavender $=$ too generalized, need to add detail, explanation, evidence, analysis and/or specificity

Green $=$ Pay attention to introduce, insert, interpret, show

Gray $=$ good points, nicely said

Red = topic sentence and/or how does this relate to or develop your thesis?

\begin{tabular}{|l|l|}
\hline $\begin{array}{l}\text { Significant and Elevates Understanding } \\
\text { Significant argument; elevating level of analysis; summary } \\
\text { used only in service of analysis }\end{array}$ & not adequately focused \\
\hline $\begin{array}{l}\text { Goal-Driven and Structured } \\
\text { Clearly stated goal; goal governs the structure of the paper; } \\
\text { use of introductory "road map," topic sentences, and } \\
\text { transition sentences; body of paper makes consistent and } \\
\text { convincing argument; each paragraph adds to reader's } \\
\text { understanding; all sentences and paragraphs are coherent } \\
\text { and follow each other logically }\end{array}$ & $\begin{array}{l}\text { Thesis too general } \\
\text { did not locate the quotes within the film }\end{array}$ \\
\hline $\begin{array}{l}\text { Supported and Effectively Analyzed } \\
\text { Appropriate amount of evidence; logical and plausible } \\
\text { analysis of evidence; active analysis of evidence (Introduce- } \\
\text { Insert-Interpret-Show) }\end{array}$ & $\begin{array}{l}\text { More time and effort is needed to develop } \\
\text { each piece of evidence }\end{array}$ \\
\hline $\begin{array}{l}\text { Executed with Clear, Engaging, and Efficient Mechanics } \\
\text { Grammar and punctuation, word choices, and sentence } \\
\text { constructions and phrases are clear, correct, and } \\
\text { appropriate; all sentences stay on task and cover ground } \\
\text { efficiently; writer maintains an appropriate level offormality }\end{array}$ & $\begin{array}{l}\text { some awkward and vague phrases that } \\
\text { need attention }\end{array}$ \\
\hline $\begin{array}{l}\text { Cinematic Elements } \\
\text { Choose at least two cinematic elements and identify three } \\
\text { enhance or strengthen your thesis about the film. }\end{array}$ & $\begin{array}{l}\text { not stated at the beginning of the paper - } \\
\text { scant attention to elements and how they } \\
\text { relate to the thesis }\end{array}$ \\
\hline
\end{tabular}

Summary: You have some very good ideas that are not well supported by the structure of your paper. In addition the lack of sharp focus defeats the paper from the beginning. Look closely at the writing consultant's comments. They provide valuable guidance on what is needed to strengthen your use of evidence. You really need to review the film and identify cinematic elements that support your thesis. Also, be sure that you identify the specific place in the film of each of the quotations or action that you discuss. Please read the assignment again (Homework \#3) and be sure that you demonstrate an appreciation of use of cinematic elements to support a theme.

Grade $=$ B-

Mandatory appointment with the writing consultant to work on how to develop a more focused thesis and support it correctly with evidence 


\section{Figure 4.}

\section{Project Assessment: Homework \#2}

Name: Student's name removed

Question \#4

Begin to observe how a scene is changed by light at different times of day. Select a location and a composition then photograph it at different times of the day. Do your best to set up the camera and tripod in exactly the same location for each time period. Choose three of these images and print them on $8.5 \times 11$ " paper for presentation on September 12.

\section{Grading Key}

+ Meets assignment extremely well, great job, just as expected

O You've done an acceptable job but there is room for improvement

$\Delta$ There are significant problems that negatively impact the success of the project

\begin{tabular}{|l|l|}
\hline $\begin{array}{l}\text { Answers the question posed } \\
\text { in the project description }\end{array}$ & $\begin{array}{l}\text { +/O The changes in light are rather subtle and the } \\
\text { subject matter according to the evaporation of } \\
\text { water in the puddles }\end{array}$ \\
\hline $\begin{array}{l}\text { Originality, uniqueness, } \\
\text { creativity }\end{array}$ & $\begin{array}{l}\text { + Interesting subject matter, nice exploration of } \\
\text { surface articulation }\end{array}$ \\
\hline $\begin{array}{l}\text { Craftsmanship, Technical } \\
\text { quality }\end{array}$ & $\begin{array}{l}\text { + Not grading significantly yet, focus is soft in one } \\
\text { image }\end{array}$ \\
\hline Composition, Design of space & $\begin{array}{l}\text { + good framing of scene which allows the eye to } \\
\text { on any particular object or color }\end{array}$ \\
\hline
\end{tabular}

Electronic Files Submitted: YES but include your name in file name next time

Overall grade and comments: Grade = A, Nice to see someone investigating subjects that are not obvious or cliché 


\section{Figure 5.}

\section{Examples of Student Projects: Self-Portraits and Staged Narratives}

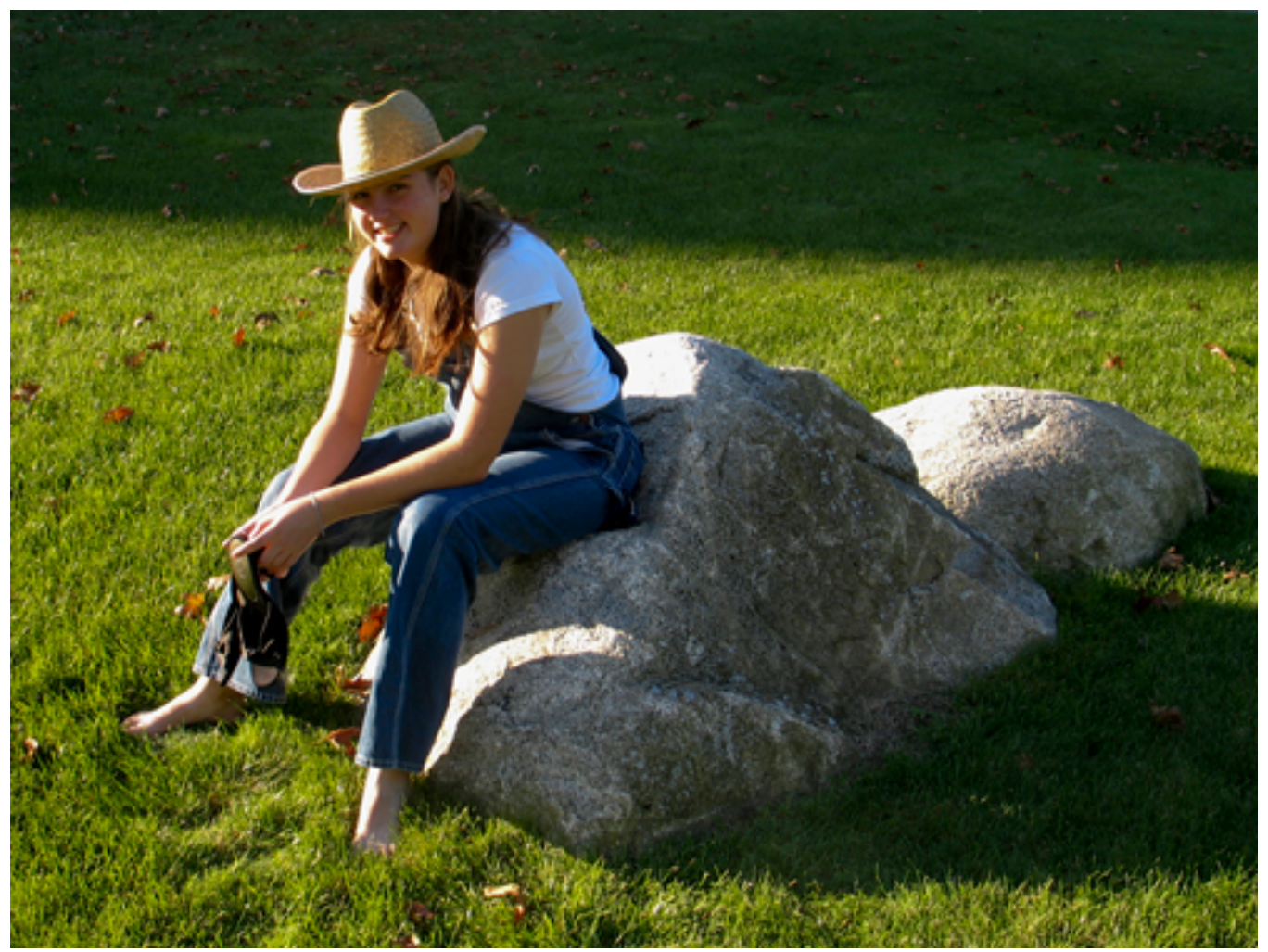

Suburban Tendencies 2007 Self-Portrait by Sarah Waskom

Most of my life I have lived in fairly affluent neighborhoods where the general attitude towards what it meant to lead a successful or fulfilling life was one of apathy, snobbery, intense materialism, or a combination of the above. People never set goals above the minimum of what they knew they could obtain, doing only enough work to get into the same college as the rest of their friends and then have the same job their parents did. The vast majority valued money and fancy cars over compassion and pursuit of knowledge. These attitudes never appealed to me, so when I moved to Iowa and met real people who were not totally focused on money and appearance, even in a comparably affluent suburb, I felt at home. Although they may perpetuate the stereotype of Iowans being hicks, I chose to wear the overalls and hat to show that I am honestly comfortable both in the clothes and as being recognized as an Iowan. Not all Iowans are farmers, just as not all of them are friendly Midwesterners. However, the people I know in Iowa are much more likely to take me for who I am, rather than what I am wearing, than any other group of suburbanites I know. The high heels symbolize the environments I grew up in. I have them in my hands as a reminder that I don't want to b ecome an appearance-crazy snob. I'm not a farmer any more than I am a pureblood Bostonian, but I will always have a place among the friendly folks I met in Iowa. 


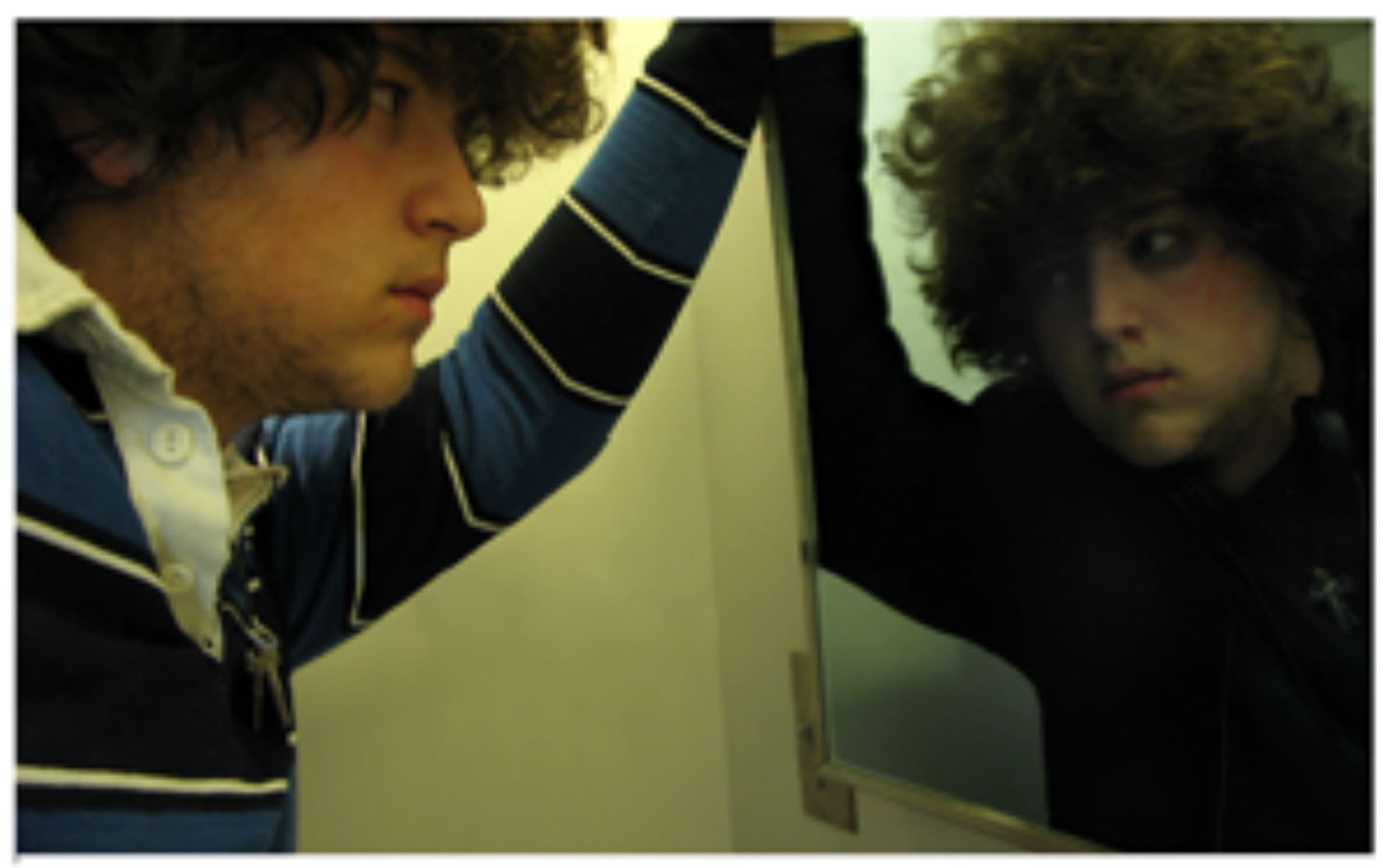

Don't Look Back 2007 Self-Portrait by John Higgins

This self-portrait portrays two very significant and different times in my life. The reflection in the mirror represents my past. I grew up on the south-side of Chicago in a relatively impoverished neighborhood with its share of gangs, crime, and violence. The reflection in the mirror represents a figure that is trying to cope with the struggles and difficulties of life in this unfortunate environment. The version of me looking into the mirror is the person that I have become. Through my pursuit of education, I have been able to leave beh ind my challenging past for a chance to change my future. The significance of this confrontation between then and now is to demonstrate the importance of my past in who I have become today. The common element of the crucifix necklace in both images shows the importance of God in both periods of my life. 


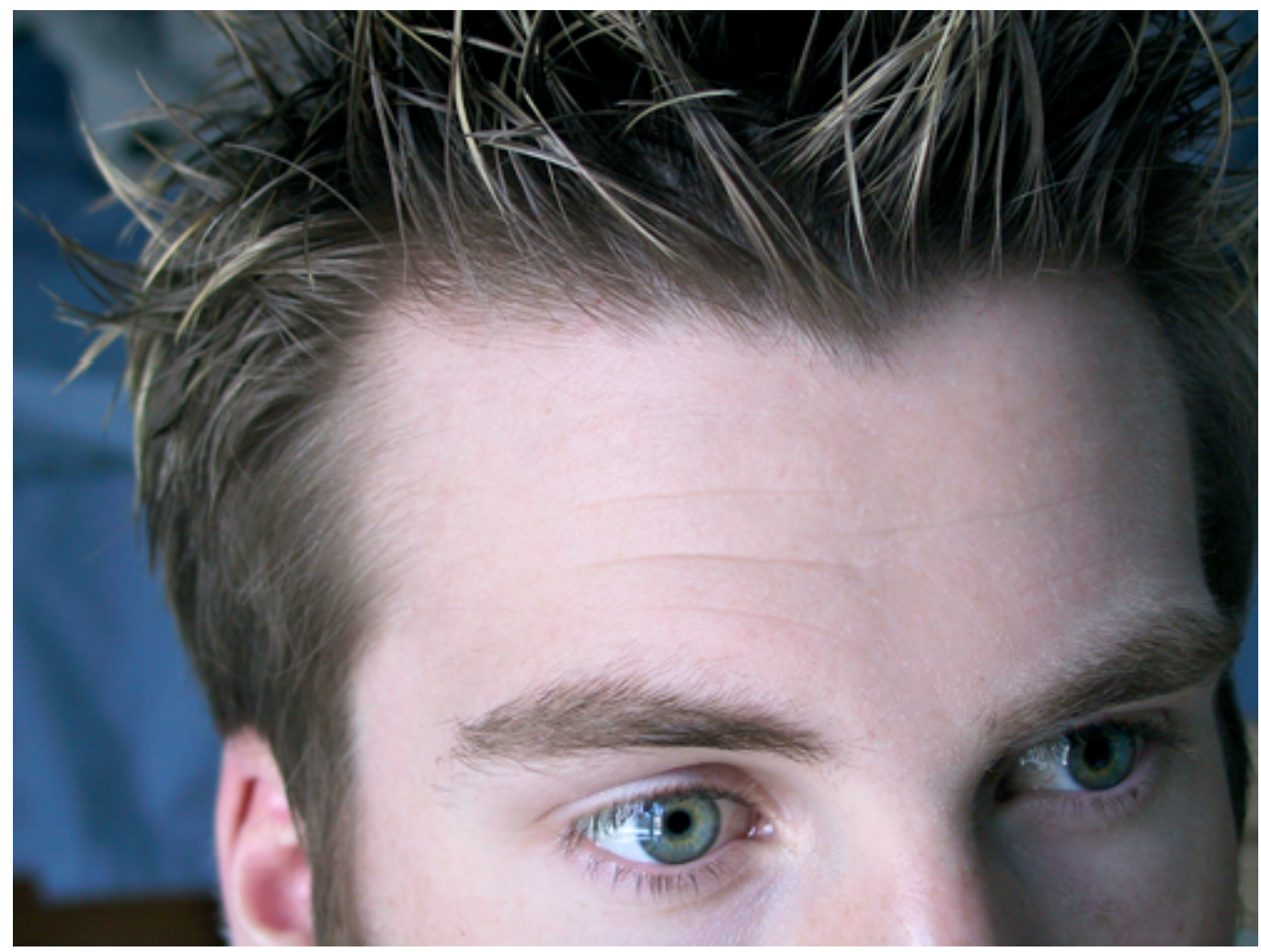

Pointed 2003 Self-Portrait by Mike Curtis

In creating this portrait, I struggled for a long time with the question of honesty. On the most basic level, I started with a real image of myself, exactly as the camera had seen. The difficulty lies in reconciling the realism of the photograph with the message I wanted to convey about how I see myself. I wanted to create an image that was both honest in the way that I physically appear, and honest with the way imagine myself. To this end, I've chosen to use digital means sparingly - to enhance the features of the image that I most wanted to call attention to: the focus of the eyes in the composition, and the confrontation contained in the expression.

I wanted to remove all sense of context from the shot, so chose a very tight composition, narrowing in on what I thought was most important in looking at myself. In a way, I think that this portrait emphasizes the reaction of my personality rather than the action. The expression represents my response to something external, and even without being able to see what that something is, the reaction itself is what's important to understanding me.

I wanted to portray a sense of directness and focus - a major part of my personality. I prefer a candid approach to resolve issues, and often thrive on confrontation as a means to find solutions. I wish to show myself as resolved, honest, and pointed. 


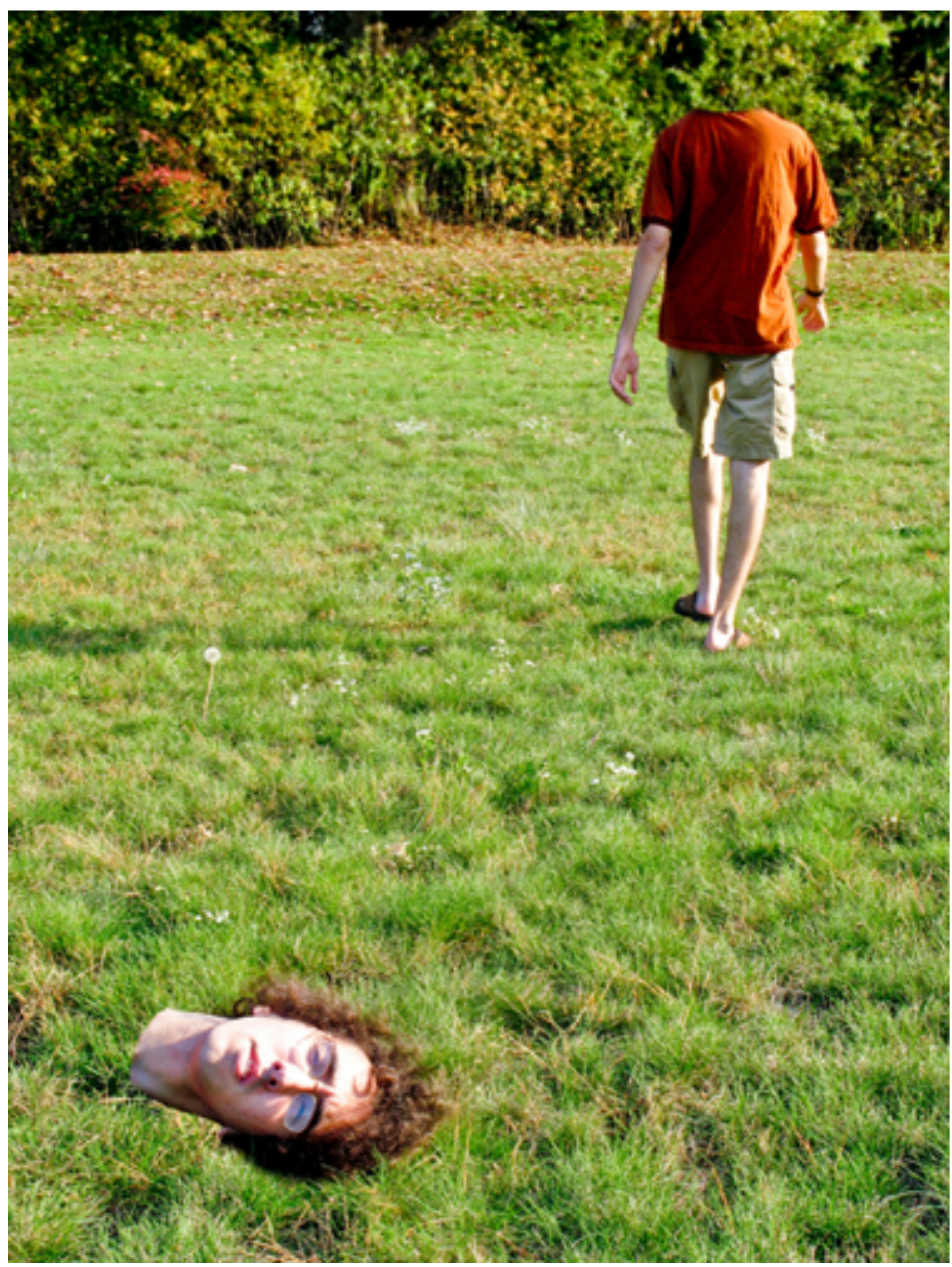

Mindless Meanderings 2007 Self-Portrait by Eli Sheldon

This image represents my practical side (my body) doing what it should be doing (say, going to class) while my mind (my head) remains rooted exactly where it was, without concern for the separation between the two halves. This expresses the frequent disconnect between where my mental focus should be and where it actually is. Quite often I find myself in a lecture or a casual conversation, and while I may be actively participating or listening, my mind is off wandering deeper thoughts that have no relevance to the topic at hand. Similarly, often when I am working on a project or thinking deeply about an issue and I then attempt to push it to the back of my mind and move on to something more practical, the thoughts soon creep back into my conscious mind and I become distracted yet again. 


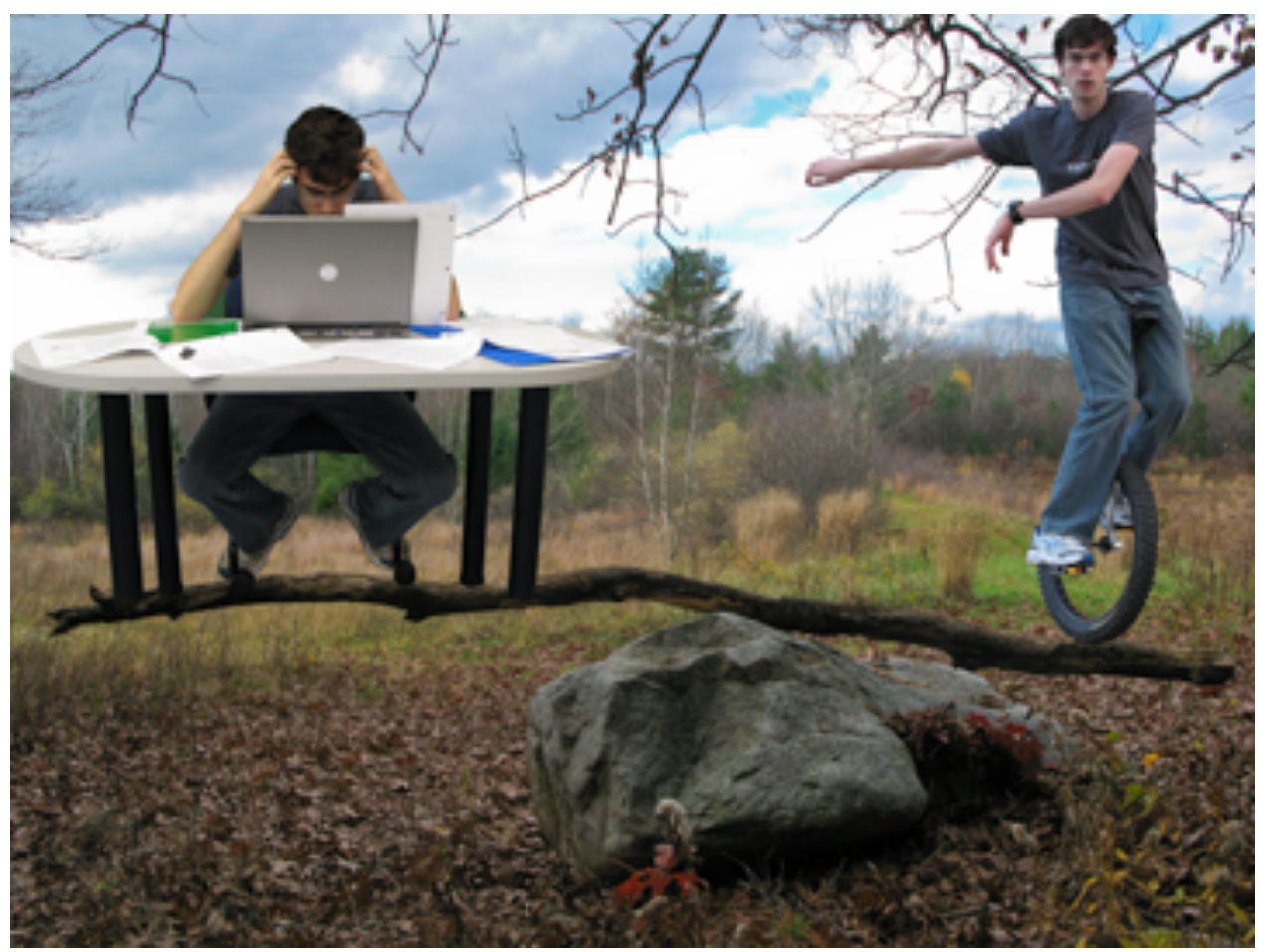

In Balance 2008 Staged Narrative by Jeffrey Atkinson

The most important aspect of college life I have found is to keep myself in balance. Any excess of work, fun, or sleep can damage the others. In this image I demonstrate the careful poise I maintain between my necessary work and my entertainment. The image is surreal to enhance its symbolism; my work and fun activities are suspended in tenuous equilibrium. My sense of balance serves as the scale, constantly reweighing my life and adjusting to find a suitable medium. The need for balance in my life is not oppressive; rather, it makes life worth living, as my ability to balance leads to fun opportunities, such as riding a unicycle. I intend to keep this sense of balance, composed just as the image, throughout my Olin career. 


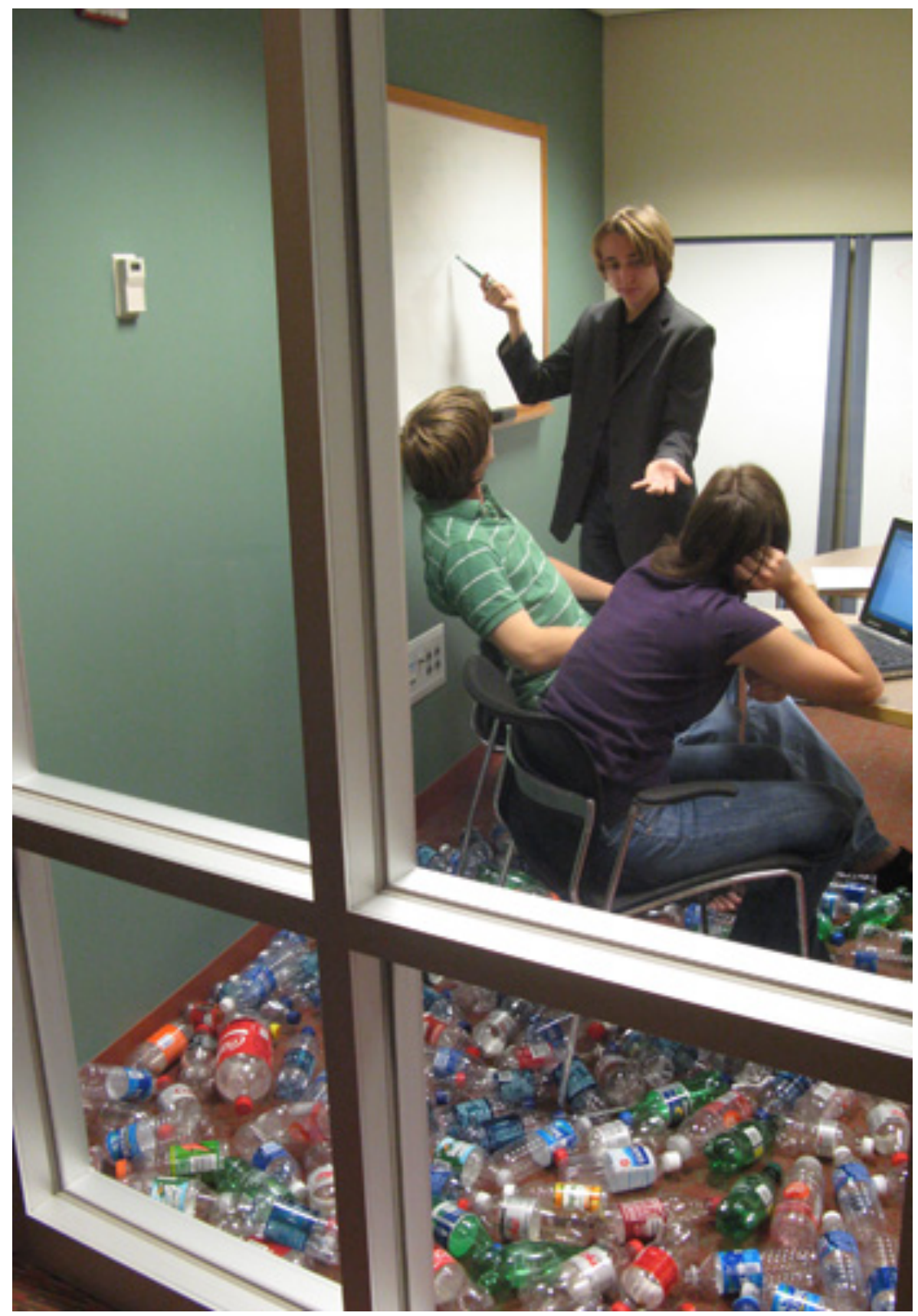

Unrecycled Recyclables 2008 Staged Narrative by Andrew Fabian

There are over 30 billion plastic bottles sold in the U.S. every year, and only about $20 \%$ of them are recycled. That means roughly 24 billion water bottles are polluting our world and filling up our landfills every year, bottles that take anywhere from 100 to 1000 years to decompose. The worst part about it is it seems that not only do people not care; they do not even notice what they are doing when they simply throw away a water bottle. At this rate people will eventually flood the world with unrecycled plastic containers, and at that point, when people have to walk on a ground littered with them, will they notice or will people just go about their lives and choose the be oblivious about the ever apparent issue as they are today? 


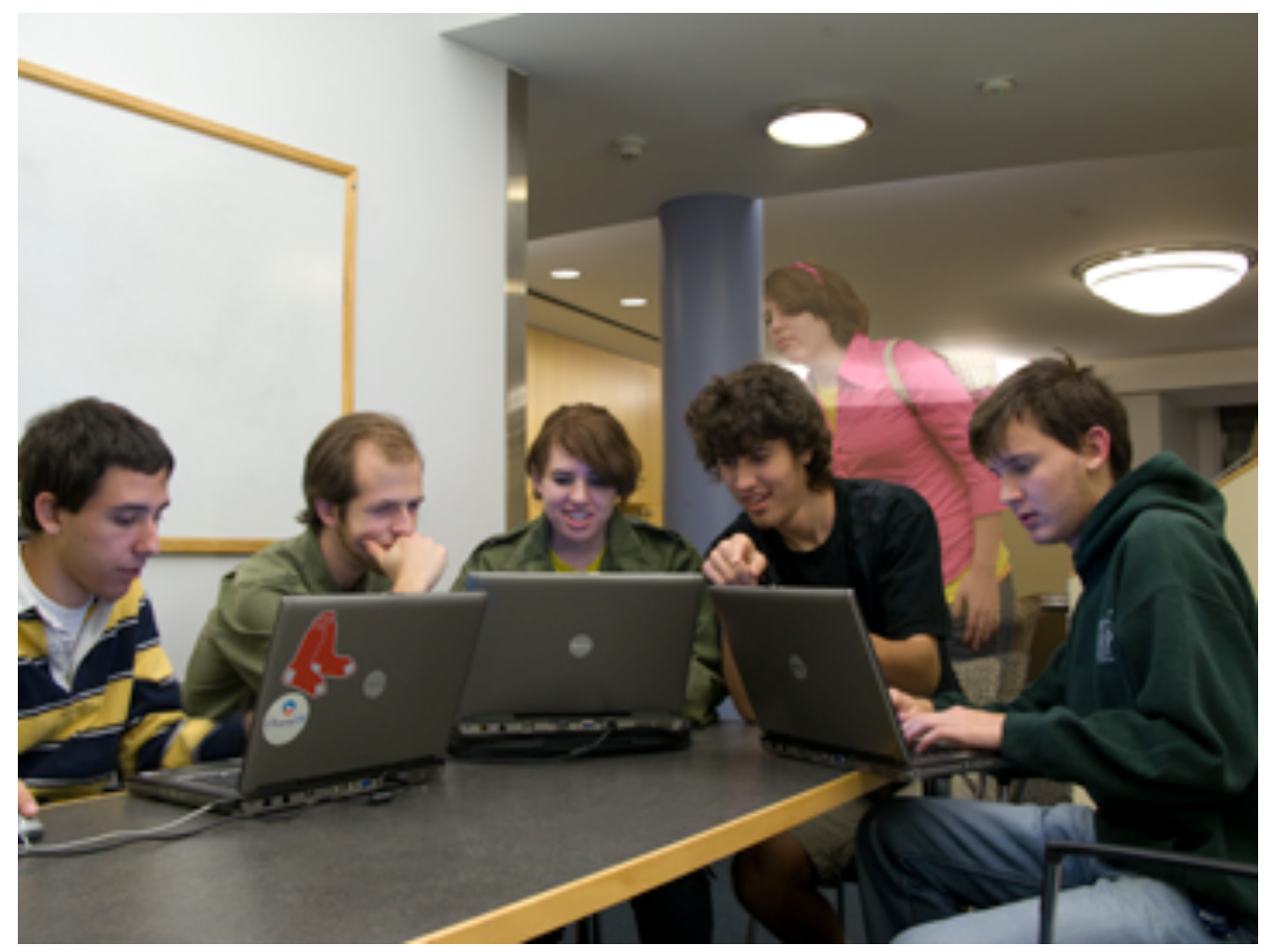

Playing with the Boys 2008 Staged Narrative by Rhan Kim

In the $21^{\text {st }}$ century, one would think that gender equality would exist by now, but even at Olin, this is not quite true. Even though the class of 2012 has a gender ratio of 40:60 girls to boys, it is very evident that the girls do not have the same presence as the boys in this engineering school.

In order to be one of the guys and be a competitive, there are a lot of pressures on a girl to lose her sense of femininity because in a male dominated world, masculinity is the key to survival. For this reason, many girls lose their sense of being a girly girl so that they can make their way through this but not every girl is quite ready to do that. At first glance, the girly girl in the background is just another girl who is unconcerned with the engineering work that is being done in the front, but after closer examination, it is easy to see that she is the same girl who has forsaken her feminine side to work in an male driven environment, such as engineering. 


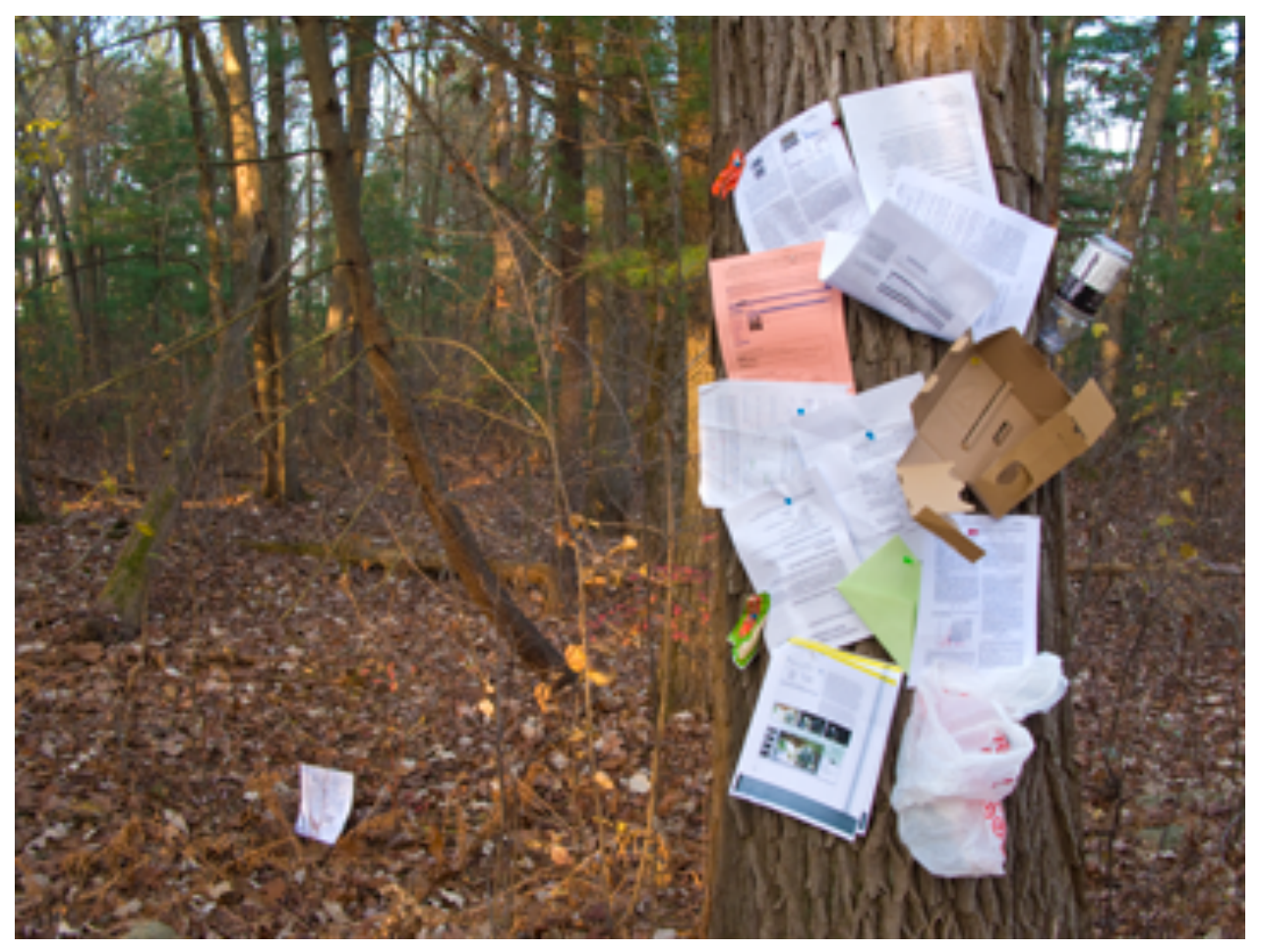

Sustainability 2008 Staged Narrative by Natalie Mattisson

Paper products have become so commonplace and so used in our society that we do not always remember that they came from trees. The photograph shows a juxtaposition between these consumer products, such as paper, cardboard, and even plastic, and a natural scene where these products might have originated from. Despite the processing involved, one must realize that all our products ultimately came from nature and its resources. It is important that we remember to recycle these materials so that we do not take too much from nature, and eventually destroy it. Additionally, we should do our best to give back to nature, by planting new trees and taking care of old ones. 